\title{
A DIRETORIA DA AGRICULTURA E OS CONFLITOS AGRÁRIOS: DIREITOS SOBREPOSTOS E DISPUTAS PELA PROPRIEDADE NO BRASIL IMPERIAL
}

Pedro Parga Rodrigues ${ }^{1}$ Marina Monteiro Machado²

Resumo: $O$ presente artigo analisa dois processos da Diretoria da Agricultura envolvendo problemas fundiários oitocentistas. Casos nos quais o escritor Machado de Assis atuou na condição de funcionário público. Ainda que não seja possível inferir destes processos as concepções machadianas sobre a propriedade, defendemos, ao longo da análise que, dada a natureza de sua posição de chefe da segunda seção da Diretoria da Agricultura, tendeu a concordar tácita ou expressamente com os pareceres de seus colegas. Contextualizamos esses processos com a realidade agrária oitocentista, elucidando ao leitor a realidade social interna e externa a essa repartição na qual o Bruxo do Cosme Velho atuou enquanto funcionário do Ministério da Agricultura, Comércio e Obras Públicas.

Palavras-chave: Propriedade. História Agrária. Conflito de Terra.

\section{THE SECRETARY OF AGRICULTURE AND AGRARIAN CONFLICTS: OVERLAPPING RIGHTS AND DISPUTES OVER PROPERTY IN IMPERIAL BRAZIL}

Abstract: The present article analyzes two processes of the Directorate of Agriculture involving eighteenth century lands problems. Cases in which the writer Machado de Assis acted as a civil servant. Although it is not possible to infer Machado's conceptions of property from these processes, we argue that, given the nature of his position as head of the second section of the Directorate of Agriculture, he tended to agree tacitly or expressly with the opinions of his colleagues. We contextualize these processes with the nineteenth-century agrarian reality, elucidating to the reader the social reality internal and external to this division in Bruxo do Cosme Velho worked as an employee of the Ministry of Agriculture, Commerce and Public Works.

Keywords: Property. Agrarian History. Lands conflict.

\section{LA DIRECCIÓN DE AGRICULTURA Y CONFLICTOS AGRARIOS: DERECHOS SUPERPUESTOS Y DISPUTAS SOBRE LA PROPIEDAD EN EL BRASIL IMPERIAL}

Resumen: El presente artículo analiza dos procesos de la Dirección de Agricultura que involucra problemas agrarios occidentales. Casos en los que el escritor Machado de Assis actuó en la condición de funcionario público. Aunque no es posible inferir de estos procesos las concepciones machadianas sobre la propiedad, defendemos, a lo largo del análisis que, dada la naturaleza de su posición de jefe de

\footnotetext{
${ }^{1}$ Universidade Federal Rural do Rio de Janeiro, Departamento de História, Rio de Janeiro, Brasil, pedropargar@gmail.com, https://orcid.org/0000-0003-4876-9073.

2 Universidade do Estado do Rio de Janeiro, Faculdade de Ciências Econômicas, Departamento de Evolução Econômica, Rio de Janeiro, Brasil, marina.machado@uerj.br, https://orcid.org/0000-00017093-3904.
} 
la segunda sección de la Dirección de Agricultura, tiende a concordar tácita o expresamente con los pareceres de sus respectivos colegas. Contextualizar estos procesos con la realidad agraria del siglo XIX, la aclaración al lector la realidad social interna y externa tal división en la que el Bruxo de Cosme Velho sirvió como funcionario del Ministerio de Agricultura, Comercio y Obras Públicas.

Palabras clave: Propiedad. Historia Agraria. Conflicto de Tierra.

\section{Introdução}

Muito já foi escrito sobre a atuação do Machado de Assis seja como romancista, contista ou mesmo jornalista. Em contrapartida, não temos a mesma expressão de estudos considerando sua atuação como funcionário público na segunda seção da Diretoria da Agricultura do Ministério da Agricultura, Comércio e Obras Públicas. Ao referir-se aos documentos do referido ministério, Sidney Chalhoub afirma: "encontrei desde o início um volume impressionante de material sobre política de terras. [...] juntei enfim uma quantidade absurda de material sobre 0 tema, que está agora a atravancar a biblioteca doméstica. Não usei nada disto neste texto" (CHALHOUB, 2003, p.11). Em sua assertiva, o historiador deixa evidente a importância do estudo da atividade de Machado de Assis enquanto funcionário do ministério, afirmando que o escritor oitocentista "formou-se ao longo dos anos 1870 em diálogo constante com a experiência do funcionário público e do cidadão" (idem, pp 138-139). Também afirma que "é possível até mesmo investigar as relações entre a experiência do funcionário e a famosa virada narrativa do romancista [...]" (idem, pp. 138-139).

Machado de Assis foi um renomado escritor oitocentista. Em sua infância, no Brasil Imperial, viveu a vida de um mulato pobre, agregado nos quadros de uma sociedade escravista e patriarcal. Seus pais eram Maria Leopoldina Machado e Francisco José de Assis. Ela era uma lavadeira açoriana, e ele, pintor de paredes liberto (MARCONDES, 2008, p. 41). A condição social de seus familiares, entretanto, não impediu Machado de alçar voos muito altos, tornando-se membro fundador da Academia Brasileira de Letras, assim como excerceu carreira de jornalista, literato, censor teatral e funcionário público em diversos cargos - amanuense, primeirooficial, auxiliar do diretor do Diário Oficial, chefe da segunda seção da Diretorias de Agricultura do Ministério de Agricultura Comércio e Obras Públicas, membro do gabinete ministerial, funcionário do ministério de Viação e Obras Públicas, etc. (MAGALHÃES JUNIOR, 1958, pp. 6, 13, 14, 18). 
Machado compôs a comissão dedicada a elaborar uma proposta de reforma da Lei de Terras de 1850 (MAGALHÃES JUNIOR, 2005, p. 243). Ainda no que diz respeito a sua aproximação com o tema das terras e da agricultura, publicou, em 1886, Terras: Compilações para estudo, trabalho que reunia os dispositivos em vigor, provenientes de diversas legislações, sobre as seguintes temáticas: terras devolutas, posses, sesmarias, terras em patrimônio, aldeamentos, registro de terras possuídas, juízes comissários, limites interprovinciais, madeiras de lei, terras aos voluntários da pátria, processos de medição de posses e sesmarias, inspetoria-geral das terras e colonização, engenheiros e agrimensores.

Reconhecemos, portanto, que Machado, largamente reconhecido por suas atividades como literato, é uma personagem complexa. Já no século XIX, demonstrou grande simpatia à causa abolicionista, embora não tenha se posicionado diretamente sobre o assunto (MAGALHÃES JUNIOR, 1958, p. 20). Nos contos "Mariana", "Virginius", bem como no poema "Sabina" evidencia sua opinião contrária ao cativeiro (idem, ibidem). Um de seus pareceres serviu de base para a decisão no Conselho de Estado sobre questão envolvendo matrícula e liberdade dos cativos (idem, pp. 24-28). Se consolidou como um clássico da literatura brasileira, reconhecido principalmente pelas suas ironias, deboches e brincadeiras, mas também por contemplar aspectos sociais corriqueiros de sua época. A existência de críticas sociais disfarçadas nos discursos dos narradores personagens de seus trabalhos ficcionais é uma das principais características da fase madura de seu fazer literário.

Machado entrou para o ministério em 1873, como primeiro oficial da diretoria central. Em 8 de março de 1880, quando seu amigo Buarque Macedo virou titular da pasta, passou a atuar dentro do gabinete ministerial. ${ }^{3}$ Permaneceu nesta função durante o mandato ministerial de seu outro companheiro ${ }^{4}$ Pedro Luís Pereira de Souza (SARTORELLI, 2016). Mas, na maior parte de sua participação no ministério, atuou como chefe da segunda seção da Diretoria da Agricultura. Foi

\footnotetext{
${ }^{3}$ Machado de Assis e Buarque Macedo trocaram cartas, nas quais se chamam de amigos e colegas mesmo antes dessa nomeação. Algumas dessas cartas foram escritas em 12/11/1875, 20/11/1875, 29/04/1879 e 27/06/1880. Em geral, tratavam de assuntos da pasta. Sobre estas cartas ver: ACADEMIA BRASILEIRA DE LETRAS. Correspondência de Machado de Assis: tomo II, 1870-1889. Rio de Janeiro: ABL, 2009. pp. 153-154, 210, 218.

${ }^{4}$ Pedro Luís escreveu para Machado de Assis doze mensagens entre 1880 e 1881. Estas missivas tratavam sobretudo de assuntos ministeriais, mas também continham outros assuntos, tais como convites de visitas, a morte de Buarque Macedo e despedida. Nessas comunicações entre eles, Pedro Luís se referia ao seu interlocutor como "meu Assis" e assinava como "teu amigo" ou simplesmente "teu". ACADEMIA BRASILEIRA DE LETRAS. Correspondência de Machado de Assis: tomo II, 1870-1889. Rio de Janeiro: ABL, 2009. P. 183, 189, 192-195, 197-201 e 203.
} 
chamado para esta função em dezembro de 1876 e para ela retornou depois de deixar o gabinete ministerial em 1881 (MAGALHÃES JUNIOR, 1958, p. 20). Essa repartição "[...] opinava cotidianamente sobre invasão de terras devolutas, demarcação e medição de terras, posses, sesmarias, terras de aldeamentos, corte de madeira e outras tantas questões fundiárias" (CHALHOUB, 2003, p. 11).

A referida diretoria nos desperta o interesse direto para os estudos sobre as relações de propriedade da segunda metade do século XIX. Era responsável por aplicar, dentre outras normas agrárias, a famosa Lei de Terras de 1850. Alguns legisladores dessa norma pretendiam nortear os direitos sobre a terra, eliminando aquilo que os liberais - defensores da propriedade absoluta e individual convencionaram chamar de confusão de limites, precariedade dos títulos e incertezas territoriais. Já que os embates cotidianos acerca dos direitos de possuir parecem ter sido o pano de fundo da sociedade oitocentista, cabia à Diretoria de Agricultura auxiliar aos demais órgãos governamentais e diretorias a lidarem com o emaranhado de direitos territoriais sobrepostos existentes, bem como a se situarem nas divergências em tornos de titulação e limites dominiais.

Atuando no ministério, o bruxo do Cosme Velho esteve diante de muitos processos que envolviam direitos de propriedade em disputa, alguns desses receberam seus comentários e assinaturas. Aqui, nos debruçaremos sobre dois deles, voltando nossos olhares para o Machado funcionário da Diretoria de Agricultura. Os autos escolhidos nos permitem refletir sobre a história da propriedade no século XIX, tendo a Diretoria da Agricultura como ponto de partida.

$O$ primeiro processo se relaciona à questão dos direitos de propriedade sobrepostos na Floresta da Tijuca, no Rio de Janeiro. A Diretoria de Obras Públicas havia comprado terras de foreiros, acreditando estar adquirindo a totalidade dos direitos sobre aquelas terras, mas na prática compravam apenas o aforamento. Aparentemente sem saber, o governo se transformava através dessa aquisição em foreiro de terceiros que, nessa ocasião, requeriam os valores que o governo teria deixado de pagar supostamente por causa de sua ignorância sobre a situação real daqueles terrenos. $\mathrm{Na}$ análise do segundo processo, voltamo-nos para um conflito sobre os limites entre terras de índios e não índios, expresso no poder de potentados locais, que avançavam suas fronteiras amplificando os conflitos agrários. Nesse segundo caso, o desconhecimento estatal sobre os limites fundiários contribuía com o constante desrespeito com relação ao direito dos nativos. 
Não se trata aqui de procurar reconstituir as noções machadianas sobre os direitos de propriedade. $O$ artigo pretende contextualizar esses processos na conturbada realidade agrária oitocentista, possibilitando refletir sobre as contingências sociais da atuação dessa personagem na Diretoria da Agricultura. Mas, sobretudo, estaremos abordando casos inseridos nas disputas pela terra em meados do século XIX. Machado, como veremos, foi sucinto, lacônico e econômico em suas intervenções, já os processos nos ajudam a revisitar o mundo agrário e as disputas envolvendo os mais diferentes agentes sociais. Entender um pouco mais essa realidade, com a qual teve contato pela perspectiva de chefe da segunda seção da Diretoria da Agricultura, elucida também a conjuntura específica com o qual esse sujeito histórico interagiu em seu fazer burocrático.

\section{Entre laudêmios, foros e a sobreposição de direitos fundiários}

Em 24 de julho de 1876, o autor do processo e suposto proprietário das terras, Joaquim Hor Meyll Alvares, "solicitou do governo o pagamento da quantia de $856 \$ 500$, proveniente de foros e laudêmio" devidos. ${ }^{5}$ Trata-se de uma preposição que a princípio nos gera certa estranheza: o governo devedor de foros. Ao adentrar o processo, no entanto, a história torna-se mais clara, ainda que bastante peculiar. Estamos diante de uma realidade na qual um senhorio, curiosamente, passa a cobrar foros e laudêmios do próprio Estado, supostamente devedor. Isto porque, nos anos de 1866, 1868 e 1875, o governo adquiriu, em negociações individuais, os territórios sob domínio útil de um conjunto de foreiros. ${ }^{6}$ Tal tipo de aquisição de áreas por parte do governo não foi uma prática incomum naquele momento, ${ }^{7}$ mas nesse caso em especial acabou gerando tantos desencontros que se converteu em processo na Diretoria de Agricultura.

Em uma relação proprietária de aforamento, acontece a repartição dos direitos de propriedade sobre um mesmo bem, passando a coexistir o domínio útil e o domínio direto. O foreiro passava a deter o domínio útil, ou seja, o direito de explorar, realizar benfeitorias, bem como deixar em herança aos seus herdeiros 0

\footnotetext{
${ }^{5}$ ARQUIVO NACIONAL. GIFI. 4B-174. N 46-J. 1877.

${ }^{6}$ ARQUIVO NACIONAL. GIFI. 4B-174. 1877.

7 Encontramos no mesmo fundo do Arquivo Nacional conjuntos de documentações, indicando que ministério da Agricultura, Comércio e Obras Públicas comprou e desapropriou em 1877 um total de oito propriedades, com a intenção de canalizar rios e construir obras ligadas ao abastecimento. A maioria delas se localizavam nas proximidades da Corte. (ARQUIVO NACIONAL. GIFI. 4B-174. 1877).
} 
aforamento e as respectivas benfeitorias. ${ }^{8}$ Já o senhorio preservava o domínio direto, cabendo-lhe receber os valores devidos, na figura do foro, da ração e do laudêmio provenientes. ${ }^{9}$ Ocorre que o governo do Brasil adquiriu apenas o domínio útil das terras, acreditando estar também adquirindo o domínio direto sobre elas. Os direitos de senhorio pertenciam, naquele momento, a Joaquim Hor Meyll Alvares, com quem o governo não havia negociado. ${ }^{10} \mathrm{~A}$ negociação ocorrera unicamente com os foreiros, tornando-se, dessa forma, foreiro de Meyll Alvares. Como o Estado desconhecia a existência do senhorio, deixou de pagar as quantias devidas ao cessionário. Em contrapartida, Meyell peticionara cobrando exatamente os pagamentos referentes aos terrenos em questão. ${ }^{11} \mathrm{O}$ desconhecimento governamental sobre a realidade agrária resultara no descumprimento de sua parte da sua obrigação, levando à demanda de Joaquim Hor Meyll Alvares.

A petição apresentada tramitou em diversas repartições até chegar às

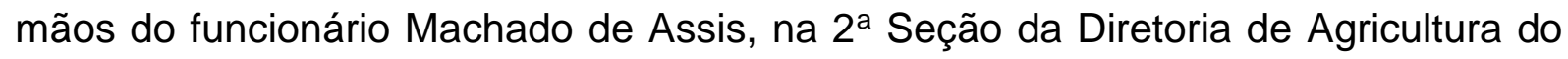
Ministério da Agricultura, Comércio e Obras Públicas. No dia 27 de outubro de 1876, o conselheiro Bernardo Augusto Nascentes de Azambuja, diretor adido do ministério, assinou um documento dirigido ao ministro da Agricultura, o conselheiro Thomas José Coelho de Almeida, tratando dessa petição. Anunciava, em seu texto, estar devolvendo o requerimento de cobrança de foros e laudêmios ao ministro, afirmando apenas: "Sobre tal assunto me conformando com o parecer do chefe da 1a Seção desta Inspetoria-Geral limito-me a passa-lo por cópia as mãos de $V$ Ex pela que resolverá como for mais justo". 12

$\mathrm{Na}$ etapa seguinte, os autos chegaram em José Inácio Coimbra, chefe da $1^{\text {a }}$ Seção da diretoria de agricultura, em 9 de outubro de 1876. Ele anunciou a necessidade de encaminhar o processo para a Diretoria de Obras Públicas do

\footnotetext{
8 Os debates acerca dos aforamentos no século XVIII foram intensos na Europa, sendo bastante criticados sob a ótica liberal, que percebia nessa relação jurídica uma imobilização do solo. Como não poderia deixar de ser, as questões atravessam o Atlântico e, imersas em suas particularidades, aparecem em processos como esse, evidenciando a realidade das terras do Brasil. MOTTA; MACHADO, 2017, p. 267.

$9 \mathrm{O}$ foro era um pagamento fixo e rotineiro, enquanto o laudêmio era pago "[...] sempre que realizada uma transação onerosa, notadamente, compra e venda do aforamento". A ração se referia a uma proporção dos produtos retirados das terras aforadas. MOTTA; MACHADO, 2017, p. 267.

10 Joaquim Hor Meyll havia comprado a propriedade direta daqueles terrenos dos herdeiros do Visconde de Asseca, o fato é comprovado por meio de uma certidão, passada pelo tabelião Pedro José de Castro, no dia 24 de maio de 1876, e anexada pelo requerente no processo administrativo em tela.

11 Dentre as questões destacadas, o sítio cujo domínio útil pertencera a Dona Luiza Rosa Sobral, o qual o governo arrematara em praça do juízo municipal de $2^{\mathrm{a}}$ vara no dia 14 de dezembro de 1868 . ARQUIVO NACIONAL. GIFI. 4B-174. 1877.

12 ARQUIVO NACIONAL. Ministério da Agricultura. GIFI. 4B-174. Documento no 679, 27 de outubro de 1876.
} 
mesmo ministério, a qual havia autorizado anteriormente a compra dos referidos terrenos, pedindo que a diretoria verificasse as escrituras pelas quais o Estado realizou a aquisição. Pretendia, de certo, compreender melhor o todo o processo até então, percebendo se o Estado de fato havia se tornado foreiro de um senhorio, procurando confirmar, inclusive, se os terrenos comprados pelo Estado seriam os mesmos referidos na petição em tela. ${ }^{13} \mathrm{~A}$ solicitação justificava-se pelo que era considerado na época uma confusão dos títulos e limites territoriais. Jurisconsultos liberais luso-brasileiros do final dos séculos XVIII e do XIX propunham criar registros e castros das propriedades, permitindo o conhecimento pelo governo dos limites e detentores de cada domínio, ${ }^{14}$ diferente do que defendiam, no Brasil, o Estado não possuía pleno controle sobre a estrutura fundiária do seu território. Alguns liberais reclamavam da permanência dos direitos territoriais sobrepostos advindos do período colonial, bem como a dificuldade de precisar os limites fundiários e a legitimidade dos títulos. Consideravam essas características de nossa estrutura fundiária obstáculos para o governo disciplinar o acesso à terra. A Lei de Terras de 1850 foi parte de um processo longo, iniciado antes dela, de pretensa individualização da propriedade. Esse processo não foi concluído no século XIX, permitindo aos proprietários utilizarem as incertezas sobre os títulos e limites territoriais para defenderem ter direitos de propriedade sobre bens alheios ou potencialmente devolutos. Por isso, José Inácio Coimbra ordenou que se averiguasse se os territórios adquiridos pelo Estado seriam os mesmos sobre os quais Joaquim Hor Meyll Alvares teria prerrogativas.

A confusão revelada nas fontes é elucidada pela solicitação de José Inácio Coimbra de informações acerca daqueles terrenos. Era preciso verificar se as terras alienadas para o governo eram as mesmas sobre a qual Meyll possuía direitos. Se as áreas que possuía e as compradas pela Diretoria de Obras Públicas fossem as mesmas, o poder público teria adquirido somente o domínio útil dos foreiros. Nesse caso, Meyll teria o domínio direto sobre as terras compradas pelo governo e, por isso, tornava-se legítima sua cobrança de foros. No caso de os alienantes terem negociado mais do que thes competia, restaria ao governo apenas "[...] o direito de proceder contra aqueles vendedores de bens alheios [...]". ${ }^{15}$ Pouco importava se 0 governo matriculou sua compra no RGI, pois esse servia apenas como prova de

\footnotetext{
${ }^{13}$ ARQUIVO NACIONAL. Ministério da Agricultura. 1ㄹ Seção. GIFI. 4B-174, 9 de outubro de 1876.

${ }^{14}$ Augusto Teixeira de Freitas, José de Alencar, Nabuco de Araújo, Domingos Vandelli, Pascoal José de Mello e Freire, dentre outros, foram exemplos dos defensores desta proposta.

${ }^{15}$ ARQUIVO NACIONAL. Ministério da Agricultura. 1ª Seção. GIFI. 4B-174, 9 de outubro de 1876.
} 
realização de um contrato de aquisição. ${ }^{16}$ Com relação aos laudêmios, o autor do parecer definia que o Estado não deveria ressarcir o petulante, pois, esses eram pagamentos de responsabilidade dos vendedores e não do comprador.

A primeira assinatura de Machado de Assis nos autos do processo administrativo em tela data de 8 de novembro de 1876, quase quatro meses após o início da contenta. No mês seguinte, Machado de Assis seria promovido a chefe de sua seção, mas, já assumia funções do cargo ${ }^{17}$. Em suas considerações, apenas reafirma com outras palavras o que já havia sido dito no parecer de José Inácio Coimbra, concordando tacitamente com o seu colega. Vejamos o texto de Machado de Assis:

O Dr Joaquim Hor Meyll Alvares, cessionário do domínio direto de diversos terrenos na Tijuca, antes pertencentes ao Visconde de Asseca, e cujo domínio útil é atualmente do Estado, por compra feita a diversos foreiros, pede que sejam pagos os foros indicados em seu requerimento e bem assim o laudemio relativo à transmissão do dominio útil do sítio de que era foreira $D$. Luiza Rosa Sobral e que pelo governo fora arrematado em praça do juiz municipal de $2^{\mathrm{a}}$ vara em 14 de dezembro de 1866.

Parece à Inspetoria das terras que os terrenos de que se trata foram comprados por autorização deste M., no intuito de aproveitar as águas ali existentes e conservar as matas em benefício dessas mesmas águas.

Parece me mais:

1ㅇ Que cumpre verificar pelo exame dos documentos (quer os que peticionário juntou a seu requerimento, quer as que o governo possuí) se as terras são as mesmas de que trata o peticionário e, se, neste caso, foi vendido ao Estado o domínio direto ou apenas o útil. Dado que fosse o útil, tem o Dr Alvares direito ao pagamento dos foros; e ainda quando fosse o domínio direto, corre ao governo a obrigação de o pagar, por isso que os vendedores, na qualidade de simples foreiros, não poderiam alienar o dominio direto dos terrenos. Ao governo restará o direito de proceder contra os vendedores.

2ㅇ Que não cabe ao governo pagar o laudêmio pela transmissão do sítio cujo domínio útil pertencera a D. Luiza Rosa Sobral, porquanto o laudêmio é pago ao senhorio direto pelo foreiro vendedor do domínio útil e não pelo comprador deste.

\footnotetext{
${ }^{16}$ A Lei Hipotecária de 1864, que versava sobre a alienação de bens imóveis, diante da ausência de uma regularização fundiária prévia, definia que o Registro Geral de Imóveis (RGI) não provava o domínio do adquirente, mas deixava esse salvo ao verdadeiro proprietário. RODRIGUES, 2016.

17 De acordo com Magalhães Jr., Machado teria sido promovido após emitir um parecer sobre matrículas de escravos, respaldado na Lei do Ventre Livre, que foi adotado pelos membros do Conselho de Estado. A decisão proposta por Machado para esse caso foi preferida pelos conselheiros, em detrimento de outras elaboradas por nomes importantes, como José Diniz de VilasBoas (oficial da Secretaria), Augusto José de Castro e Silva (antigo diretor de Agricultura), José Pedro Xavier Pinheiro (oficial da Secretaria), Francisco Leopoldino Gusmão Lobo (chefe da Diretoria Central). MAGALHÃES JUNIOR, 2005, pp. 240-243.
} 
A Inspetoria das terras entende conveniente reunir-se a Inspetoriageral de Obras públicas por onde pensa que foi realizada a compra dos terrenos de que se trata.

A esta seção parece que estes papéis devem ser transmitidos à Diretoria das obras públicas que informará e ouvirá a inspetoria, devolvendo-os depois à diretoria de agricultura com os esclarecimentos necessários. ${ }^{18}$

Os encaminhamentos escritos por Machado de Assis para o processo aberto por Joaquim Hor Meyll Alvares reproduziam as orientações elaboradas pela Inspetoria de Terras Públicas e Colonização. Trata-se de um texto técnico do funcionalismo público, no qual Machado apenas reafirma o parecer de seu colega, sem emitir concepções próprias sobre a propriedade. O texto revela, entretanto, 0 contato, pelas vias institucionais, com as questões fundiárias oitocentistas. Ao acompanhar o encaminhamento da inspetoria de que era necessário "[...] verificar [...] se as terras são as mesmas de que trata o peticionário [...]", o diretor da sessão evidencia as dificuldades de precisar os limites e titularidades territoriais, destacando a existência das fraudes que regularmente ocorriam no exercício da prática proprietária. Reconhecemos no discurso a compreensão sobre a aplicação da Lei de Terras de 1850, na qual a ausência de uma regularização fundiária exigia uma averiguação da titularidade, limites e localização dos direitos pleiteados.

Chama atenção, no entanto, a sua conclusão. Em fevereiro do ano seguinte, o autor do processo propôs vender à secretaria de obras públicas os seus direitos sobre aquelas terras, eliminando a sobreposição de direitos existente

Joaquim Hor Meyel Alvares propôs [...] a remissão do domínio direto dos terrenos sitos na floresta da Tijuca, cujo domínio útil já Ihe pertence [...] venda de dois outros no sitio denominado da Taquara, por interessarem a compra dos mananciais ali tomados para o abastecimento $[\ldots]{ }^{19}$

O governo imperial passaria a deter ambos os domínios: útil e direto. Construía-se a individualização daquelas propriedades, de acordo com a ótica marcadamente liberal. Porém, isto não ocorria como um processo sistemático de individualização, mas como resposta a um processo específico motivado pela compra das terras realizada pela Diretoria de Obras Públicas. Adquiriram-se os direitos de Meyell, tornando-se detentor dos domínios útil e direto sobre aqueles terrenos.

\footnotetext{
${ }^{18}$ ARQUIVO NACIONAL. GIFI. 4B-174. 1877.

${ }^{19}$ ARQUIVO NACIONAL. GIFI. 4B-174. 1877.
} 
Ainda que muitas vezes o governo não aparentasse o empenho em regularizar a estrutura fundiária nos padrões liberais, tornando-a incondicionada e individual, é possível perceber as ações isoladas para remir a propriedade através de operações de compra dos diferentes direitos existentes sobre aquelas terras. Esse método de singularização dominial diferia, por exemplo, de algumas propostas existentes em Portugal. Diante do exposto, reconhecemos que existiram diferentes, e não necessariamente convergentes, defesas de individualização da propriedade. ${ }^{20}$ A realidade era complexa e um tanto delicada, dividindo inclusive os juristas contemporâneos. Para alguns, essa eliminação dos direitos sobrepostos deveria sacralizar os domínios senhoriais, enquanto para outros, os foreiros deveriam ter seus direitos protegidos. ${ }^{21}$ No caso em tela, o governo pretendia adquirir os direitos de ambos os lados.

Não é possível afirmar que o Império brasileiro tenha atuado de forma sistemática no sentido de individualizar a terra. Percebemos, no entanto, um movimento de transformação que ocorreu paulatina e desorganizadamente, com variações e especificidades em cada região. O Estado apenas atuou por meio de operações de compra e venda, nas quais adquiriu o domínio útil e mais tarde, supomos, o domínio direto. Essa atuação governamental é coerente com uma determinada forma de conceber a propriedade existente no interior do Ministério de Agricultura, Comércio e Obras Públicas, segundo a qual o Estado não deveria intervir nos territórios de mando senhorial, abstendo-se de regularizar o solo sem o consentimento dos proprietários (RODRIGUES, 2017).

Esse entendimento esteve presente na aplicação da Lei de Terras de 1850, longe de ser explicada pelo "veto dos barões" à tentativa governamental de organizar a estrutura fundiária, a aplicação rigorosa dessa norma foi questionada mesmo por ministros da época. ${ }^{22}$ Os titulares da pasta, embora reclamassem do que consideravam insucessos na aplicação dessa legislação, questionavam a possibilidade de aplicá-la meticulosamente, regularizando a estrutura agrária. No relatório de 1877, por exemplo, o ministro João Lins Vieira C. de Sinimbu apresenta

\footnotetext{
${ }^{20}$ Concordamos aqui com: MOTTA; MACHADO, 2017, pp. 269 e 272.

${ }^{21}$ MOTTA; MACHADO, 2017, pp. 269 e 272.

22 A tese do "veto dos barões" foi defendida por José Murilo de Carvalho (1981). Para ele, essa norma teria sido proposta por uma elite política, mas vetada na prática pelos barões. Essa percepção foi, entretanto, criticada por vários historiadores. Márcia Motta (1998) foi a pioneira nessa crítica, demonstrando como essa norma foi utilizada por diferentes agentes sociais, negando a perspectiva segundo a qual essa norma não teria efeito prático. Cristiano Christillino (2010) apresentou a própria Coroa permitindo uma fração da elite sul-rio-grandense utilizar essa norma, em troca de seu apoio para a construção de um Estado centralizado.
} 
essa postura. Para ele, "Apesar da solicitude com que o governo há procurado dar execução à Lei n. 601 de 18 de setembro de 1850, a intenção do legislador está longe de haver sido satisfeita" (BRASIL, 1876, pp. 394-395), pois "a descriminação das terras dos domínios particular das do domínio público, indispensável ao preenchimento dos fins daquela Lei, está ainda por fazer [...]" (idem, ibidem) e as "Terras públicas têm continuado a ser invadidas [...]" (idem, ibidem). Segundo Sinimbu, "[...] a Lei de Terras tem-se tornado quase letra morta em vários pontos [...]" (idem, ibidem). Mas além de reclamar da aplicação da norma, o ministro também afirma a necessidade de uma moderação estatal na aplicação desse marco legal, pois "[...] graves interesses de ordem pública não aconselham a rigorosa aplicação das disposições legais" (idem, ibidem). Para ele e alguns outros agentes do ministério, era necessária a anuência dos proprietários para estabelecer os limites territoriais precisamente e separar os títulos válidos dos caídos em comisso. Tratava-se de pensar a política agrária através de uma noção de propriedade para a qual a fazenda era local de mando dos potentados rurais. Essa noção adiava a possibilidade de reorganizar a estrutura fundiária, perpetuando o descontrole estatal sobre o território.

Por descontrole estatal sobre o território, entendemos as dificuldades do governo em manter registros ou cadastros contendo os proprietários e limites dos imóveis, bem como de diferir facilmente os títulos capazes de provar direitos. Alguns legisladores e aplicadores da Lei de Terras de 1850 e da Lei Hipotecária de 1864 defendiam propostas de regularização da estrutura fundiária, tentavam delimitar as fronteiras territoriais, bem como distinguir os títulos com validade jurídica dos caídos em comisso. Os legisladores dessas normas desejavam criar um cadastro de terras possuídas e um registro dos detentores de imóveis, visando permitir a fácil apuração dos donos e limites de cada domínio. O resultado final da promulgação e aplicação desses dispositivos jurídicos, entretanto, não deram conta de assegurar ao governo - e aos demais interessados - a fácil consulta de quem seriam os proprietários, os limites precisos e os títulos válidos de cada terra. No processo em tela foi necessário um estudo mais apurado para averiguar se o requerente possuiria de fato direitos sobre os domínios que alegava. O título apresentado não dava conta de comprovar a validade daquilo que declarava. Foi necessário consultar especialistas no assunto. 


\section{Conflitos e disputas nas terras do Aldeamento de Riacho do Mato}

Partimos agora para a análise do segundo processo selecionado. Um caso complementar ao primeiro, já que ambos evidenciam embates por terras vividos no Império do Brasil e estão relacionados com o desconhecimento do Estado sobre as especificidades da ocupação do território. O resultado está expresso nos conflitos e disputas decorrentes de realidades sobrepostas da posse das terras. Em de agosto de 1877, a $2 \underline{a}$ seção do Ministério de Agricultura e Obras Públicas recebeu a solicitação do padre José Barbosa Menezes. O religioso, em requerimento de 20 de fevereiro desse mesmo ano, solicitava que o Estado Ihe vendesse terras do extinto aldeamento do Riacho do Mato. De acordo com o autor, esses quinhões já estariam em seu poder. A solicitação referia-se às terras situadas em uma área próxima à divisa entre as então províncias de Pernambuco e do Alagoas (SILVA, 1995, p. 79). Região margeada por diversos rios, dentre eles Jacuípe-Mirim, Taquara e o Riacho do Mato, águas fluviais que tornavam as áreas férteis, propícias para o plantio de cana-de-açúcar, café e algodão (idem, ibidem).

Nas redondezas estavam localizados engenhos, colônias agrícolas e o Aldeamento Indígena de Riacho do Mato. Esse último era composto por grupos indígenas removidos do Aldeamento de Escada, ${ }^{23}$ além de outros provenientes da Aldeia de Jacuípe. Completavam a população da região grupos de posseiros, assim como remanescentes da revolta de Cabanada, ${ }^{24}$ denominados nas fontes como

\footnotetext{
${ }^{23}$ Há relatos de que a Aldeia da Escada teria sido fundada ainda no século XVI, mas o que nos interessa aqui é a trajetória deste Aldeamento no século XIX, quando os registros assumem que os grupos indígenas receberam a doação de uma sesmaria de uma légua em quadra como recompensa pela participação nos combates ao Quilombo dos Palmares, a qual foi acrescida com a compra de outra légua por parte dos próprios indígenas. Considerada a mais rica da província, a Aldeia da Escada despontava por situar-se em uma região fértil que, se por um lado favoreceu que seus moradores mantivessem uma vida economicamente estável, por outro lado despertou os interesses e ambições de não índios que passaram a ocupar as terras por meio de arrendamentos e aforamentos, construindo nesse espaço uma nova realidade de ocupação que logo passou a não mais legitimar a presença e os direitos dos grupos indígenas então estabelecidos. Sobre o Aldeamento de Escada, Cf.: SILVA, 1995, pp. 37-45.

24 Segundo o Dicionário do Brasil Imperial, a Cabanada, ou Guerra dos Cabanos foi um expressivo movimento do período regencial que eclodiu em 1832 ao sul de Pernambuco, expandindo-se para o norte do Alagoas até o ano de 1835, quando a maior parte do movimento foi morta ou presa pelas forças legais. Contou com forte participação de segmentos populares, cujas moradias precárias foram identificadas como cabanas, dando nome a rebelião. Destaca-se por ser uma revolta armada de grande pluralidade étnico-racial, com uma base popular diversa que contou com trabalhadores livres (conhecidos como moradores), pequenos produtores, negros forros e escravos fugidos. Grupos indígenas aldeados à margem do rio Jacuípe também entraram no conflito, protagonizando disputas diretas com os proprietários locais pela posse das terras. Envolvendo uma área de expansão para grandes propriedades e, portanto, polo de atração para trabalhadores livres, desapropriados e cativos fugidos. Assim, em seus múltiplos significados, a Cabanada aponta para a diversidade que marcou o movimento. Entre elites que aspiravam reestabelecer os privilégios dos quais gozavam no primeiro reinado à intensa participação popular que se via ameaçada pelo avanço avassalador da economia
} 
moradores. Nessa insurreição pretérita, enfrentaram-se tropas provinciais e os habitantes dos mocambos mistos, constituídos por grupos indígenas aldeados, moradores, colonos e mestiços, bem como escravos fugidos (MELLO, 2005, p. 1). As memórias da Cabanada eram fortes na região, rotineiramente acionadas para hostilizar a população indígena, deslegitimando sua presença no local (SILVA, 1995, p. 79).

De acordo com os estudos do historiador Edson Hely Silva, o Aldeamento do Riacho do Mato foi criado a partir das ações do índio Manoel Valentim dos Santos, morador do antigo Aldeamento da Escada (SILVA, 1995). Diante das invasões das terras que ocupava, por arrendatários e foreiros, Valentim, acompanhado por Jacinto Pereira da Silva, viajou diretamente à corte no Rio de Janeiro, em 1861, para solicitar a transferência dos índios para o Riacho do Mato. Existiram rumores acerca da viagem ter sido custeada por senhores de engenho, mas, aparentemente resultou em significativas conquistas para os grupos indígenas. Um Aviso do Ministério da Agricultura a Presidência da Província de Pernambuco determinou a medição e a demarcação de uma área no Riacho do Mato para o estabelecimento dos grupos indígenas, bem como foi reconhecido o novo Aldeamento. Em Aviso posterior, determinou-se a remoção dos índios que ainda habitavam a Aldeia da Escada para o Riacho do Mato, e a primeira considerada extinta. A remoção dos índios para a nova localidade foi questionada por poderosos locais, potentados recorriam a memória sobre o passado conflituoso daquela região contra o reassentamento dos grupos indígenas. Instrumentalizavam, sobretudo, os temores relacionados ao fato do Arraial do Riacho do Mato abrigar os remanescentes do contingente aguerrido que, sob a liderança de Vicente Ferreira de Paula, atuaram na revolta da Cabanada. ${ }^{25}$

Os aldeados de Escada, liderados por Manuel Valentim dos Santos, foram transferidos para a nova localidade, e logo lançaram mão de estratégias que tinham por objetivo garantir seu estabelecimento e permanência nas novas terras (apud SILVA, 1995, p. 73). Elaboravam apelações para autoridades, abaixo-assinado e

açucareira. Mesmo após a derrota, tendo muitos chefes cabanos se entregue às autoridades, durante cerca de 15 anos continuaram ocorrendo ataques aos engenhos para libertação de escravos no interior de Pernambuco e Alagoas. ENGEL, 2002.

Sobre Cabanada, Cf. MELLO, 2008.

${ }^{25}$ Alguns autores afirmam que antes de toda a luta burocrática pelos direitos dos grupos indígenas e a construção do aldeamento, o índio Manuel Valentim dos Santos teria lutado ao lado do líder cabano Vicente Ferreira de Paula na década de 1840. A localidade do Riacho do Mato também não é casual, tendo sido essa a localização onde os remanescentes do contingente aguerrido se estabeleceram sob a liderança de Vicente Ferreira de Paula. Sobre este aspeto, Cf.: OLIVEIRA, 2015. MELLO, 2008. 
recorriam aos meios possíveis para atingir seus objetivos. Dentre os recursos utilizados e argumentos apresentados, pontuaram a atuação no combate ao quilombo dos Palmares, a cessão de voluntários para a Guerra do Paraguai e para as milícias legalistas, por exemplo (apud SILVA, 1995, p. 82). Procuravam enfrentar a pecha de desordeiros e incivilizados, utilizando uma prática comum desde 0 período colonial, apresentando-se como fiéis à Coroa e à ordem, ao mesmo tempo em que peticionavam a graça do acesso à terra. A experiência anterior dos grupos indígenas de Escada nos "esbulhos sistemáticos" em sua antiga morada tornava ainda mais aguda a necessidade por garantias para sua estadia no novo aldeamento (SILVA, 2016, pp. 1-2). Representaram, de certo, um tempo de aprendizagem, estratégias e recursos, dos quais lançariam mão para assegurarem seus direitos territoriais.

Assim como em outras regiões do Império, foram muitos os conflitos ocorridos durante o processo de estabelecimento dos grupos indígenas do extinto aldeamento de Escada na região do Riacho do Mato. ${ }^{26}$ Em 1861, Manuel Valentim e outros índios se envolveram em uma disputa direta com Manuel Francisco Jatobá Canuto, o mesmo que, supostamente, teria vendido às terras ao padre José Barboza Menezes, anos depois (SILVA, 1995, p. 74). Canuto era uma figura de muito poder e influência na região. Exercia o cargo de inspetor de quarteirão, possivelmente em retribuição à sua atuação no combate aos Cabanos (idem, ibidem). Era membro da Guarda Nacional daquela localidade. Isto demonstra que possuía a renda mínima para ser eleitor, 100 mil réis. ${ }^{27}$ Vivia no Engenho do Espinho, nas terras da Colônia Leopoldina.

Em 1861, Manuel Francisco Jatobá Canuto acusou Manuel Valentim, e um grupo de vinte índios, de fazer roças sem autorização em área próxima de sua casa, causando pânico no Sítio do Espinho, situado pouco mais de duas léguas da residência destes grupos indígenas (idem, ibidem). Afirmava ser, desde muito tempo, "alvo da ojeriza e animadversão dos índios" (idem, ibidem). O ofício de sua autoria ao Diretor da Colônia Militar de Pimenteiras, além dessas denúncias, provocava ainda alarde sobre um suposto retorno de Vicente de Paula, líder Cabano, para Pernambuco (idem, ibidem). Como se pode perceber, Canuto

${ }^{26}$ Sobre os conflitos envolvendo disputas em áreas consagradas pela ocupação indígena, cf. MACHADO, 2012.

${ }^{27}$ A Guarda Nacional, organizada em 1831, era uma força militar inspirada nas milícias cidadãs francesas e preocupada com a manutenção da ordem. O critério para atuar nessa tropa era ser um cidadão eleitor, em uma época na qual o voto era censitário. A concepção do "cidadão armado" fundamenta a instituição, que se insere no conjunto de medidas descentralizadoras. 
instrumentalizava a memória sobre a Cabanada, promovendo medo com relação aos grupos indígenas locais, ao mesmo tempo em que resgatava sua atuação no combate a essa insurreição, de forma a indicar o merecimento de graças.

Esse não foi, no entanto, o único recurso mobilizado por Canuto contra seus adversários indígenas. No mesmo ofício, em que os acusava de invadir suas terras, operava o imaginário sobre os grupos dos nativos questionando suas identidades e, de certa forma, desmerecendo seus direitos. Ele descreveu o líder e a composição dos supostos invasores respectivamente como "um cabra negro intitulado por índio" (idem, ibidem) e "20 a vinte e cinco cabras armados, entre esses alguns índios" (idem, ibidem). Utilizava a miscigenação, típica da região, para deslegitimar aqueles que se apresentavam como indígenas, provenientes do extinto aldeamento de Escada. Uma prática que pouco nos surpreende. Diante da legitimidade do direito à terra dos índios, era comum desconsiderar a identidade para assim Ihes negar um direito. ${ }^{28}$

Esse não foi o único conflito com grupos indígenas no qual a família Canuto esteve envolvida. No ano de 1869, durante o processo de demarcações e medições das terras, foram muitas as divergências entre grupos indígenas e os posseiros (idem, pp. 84-85). Os aldeados sentiram-se sempre lesados pelo processo de demarcação das terras, asseverando às autoridades que estavam sendo legalizadas posses de invasores no interior do aldeamento (idem, p. 85). Manuel Valentim dos Santos denunciou autoridades locais - o presidente da província de Pernambuco, o juiz comissário e o engenheiro-chefe, responsável pela demarcação -, acusando-os de beneficiar posseiros em detrimento dos direitos dos grupos indígenas. A forma com que a demarcação foi operada deixava aos grupos indígenas apenas "as sobras destas supostas posses, terrenos montanhosos, cortados por fracos riachos e que se estinguem com qualquer verão mais forte [...]" (idem, ibidem). As acusações foram confirmadas pelo diretor-geral dos índios, Francisco Camboim, que as complementou, expondo os responsáveis pela medição de aceitarem subornos para privilegiar aos posseiros (idem, ibidem). Tanto o diretor quanto Valentim apontaram nomes coincidentes de posseiros favorecidos pelas fraudes na demarcação. Dentre eles, sem grande surpresa, deparamo-nos com o

${ }^{28} \mathrm{O}$ Regulamento da Lei de Terras de 1850 reconhecia o direito dos grupos indígenas aldeados e civilizados às terras que ocupavam. Assim, não foram raras as vezes em que percebemos a prática de desconsiderar a identidade dos grupos indígenas, tratando-os como mestiços ou caboclos, e, portanto, não merecedores das terras ocupada por eles. Ao negar suas identidades indígenas, seus rivais questionavam a aplicação dos dispositivos jurídicos que lhes asseguravam direitos com base na sua origem. Sobre este aspecto ver: MACHADO, 2007. MACHADO, 2012. 
nome de Antônio Francisco Jatobá Canuto, filho do inspetor de quarteirão, o mesmo que denunciara os grupos indígenas, oito anos antes, em 1861.

A dificuldade em precisar os limites, as disputas por terras e pelo direito de propriedade na segunda metade do século XIX precisam ser compreendidas historicamente. Ao longo do período colonial, a Coroa Portuguesa distribuiu terras em forma de sesmarias, por vezes sobrepostas, à diferentes súditos. ${ }^{29}$ Além disso, nesse contexto, a propriedade possuía um significado bastante diferente do atual. Inicialmente, não era absoluta, mas sim condicionada. Desse modo, não bastava possuir o título, era preciso cumprir determinadas condições para ter direito dominial, como o povoamento e o cultivo das terras. Os títulos de sesmarias não representavam garantias, ou provas de propriedade, fazendo-se necessário averiguar a ocupação. Em segundo lugar, o direito naquela época apresentava-se menos individualista, permitindo que diferentes pessoas possuíssem direitos diversos sobre um mesmo bem (PEDROZA, 2016). Parte desses direitos eram costumeiros, não estando regulamentados em nenhuma legislação. ${ }^{30}$

A já mencionada Lei de 1850 foi promulgada com o propósito de individualizar a propriedade, tornando-a absoluta, por meio da regularização da estrutura fundiária do país. Dentre outras finalidades, pretendia, oficialmente, estabelecer limites territoriais precisos e garantir a concessão de títulos confiáveis. No entanto, ainda que tenha sido acionada em diversos conflitos agrários oitocentistas, foram poucas as regiões onde esse processo de regularização fundiária de fato ocorreu. Deve-se reconhecer sempre a complexidade dessa Lei, a difícil conjuntura de debates e as dificuldades de sua implementação, destacando ainda que sua regulamentação destinou alguns artigos específicos para as áreas ocupadas por grupos indígenas. É preciso reconhecer, já a priori, que a Lei de

${ }^{29}$ Para uma reflexão sobre a Lei de Sesmarias portuguesa, sua transplantação para a realidade da colônia e as problemáticas decorrentes, ver: MOTTA, Márcia Menendes. Direito à terra no Brasil: a gestação do conflito - 1795-1824. São Paulo: Alameda, 2009.

30 Segundo António Manuel Hespanha, na Época Moderna, "[...] a maior parte da vida jurídica ocorria à margem do direito escrito [...]" (1993, p. 15). Com a propriedade imóvel, não era diferente. Paolo Grossi (2006, p. 37), um dos erros a serem evitados pelos historiadores da propriedade seria 0 formalismo, que consiste em reduzir esse direito às leis ou atos emanados do Estado. $\mathrm{O}$ autor ressalta a possibilidade de as fontes jurídicas serem utilizadas em diferentes caminhos, fazendo surgir relações entre homens e bens diversos. Os costumes podiam ser apropriados de forma distinta pelos diversos grupos sociais ao longo do tempo, de acordo com Thompson (1998, pp. 86-149). Rosa Congost (CONGOST, 2007, p. 18.) critica o que chama de visão estatista sobre as transformações das práticas proprietárias, pois podem surgir relações dominiais diferentes sob a égide de uma mesma norma ou a despeito de qualquer legislação. Nessa perspectiva, questionada pela historiadora, os estudiosos se prendem ao direito produzido pelo governo para pensar as transformações da realidade agrária, perdendo, assim, as permanências de práticas jurídicas costumeiras anteriores, a diversidade na aplicação das normas, bem como a pluralidade de outras práticas proprietárias existentes nas margens dos marcos legais. 
Terras chegava a público com um grande desafio: organizar a ocupação fundiária de uma nação em processo de consolidação. Diante da existência de direitos sobrepostos e das incertezas sobre os limites, herdados do período colonial, surgiam impasses. A expectativa, presente em alguns dispositivos dessa norma, de regularizar domínios, estabelecendo limites precisos e averiguando os títulos, representaria sacralizar os direitos de alguns em detrimento de outros. Nesse processo, a norma de 1850 podia ser operacionalizada em diversos sentidos, priorizando diferentes grupos sociais. Ao que nos parece, na região do Riacho do Mato, ela foi utilizada em favor de poderosos posseiros, incomodando diretamente os grupos indígenas. Somava-se a isto a existência de subornos e práticas fraudulentas. ${ }^{31}$

Em 1873, o presidente da província de Pernambuco determinou extinto o aldeamento do Riacho do Mato. Ordenou, portanto, a demarcação em lotes as terras do referido aldeamento, onde passariam a viver as famílias indígenas, definia por fim que as áreas sobressalentes seriam vendidas em hasta pública. A demarcação das terras, reiniciada em 1875, pretendia corrigir as demarcações fraudulentas, dentre elas a de Canuto. Os estratagemas dos posseiros, entretanto, estavam longe de ter fim. Apenas dois anos depois, a disputa entrava em uma nova fase e o processo chegava às mãos de Machado de Assis, na Diretoria do Ministério de Agricultura, Comércio e Obras Públicas. As terras desse mesmo aldeamento eram pleiteadas para compra e seguiam em litígio, e os principais nomes envolvidos nos conflitos reaparecem com força, como personagens centrais nessa nova etapa das dissensões.

\section{A atuação de Machado no processo}

Foi no dia 3 de agosto de 1877 que o requerimento do padre José Barboza Menezes começou a ser analisado pela 2 a seção do Ministério de Agricultura Comércio e Obras Públicas. ${ }^{32}$ Como já mencionamos, tratava-se justamente da repartição que, desde 1876, era chefiada por Machado de Assis. O padre solicitava

\footnotetext{
${ }^{31}$ Márcia Motta apresenta uma realidade agrária onde existiam pequenos e grandes posseiros. De acordo com a autora, o costume da posse era compartilhado por diferentes atores sociais, restando, entretanto, aos homens pobres livres o mito do invasor. Enquanto as posses desses agentes eram hegemonicamente consideradas delitos, os fazendeiros se apropriavam de terras indígenas e devolutas pela porta dos fundos de seus domínios. A autora nos lembra ainda que a palavra na acepção que hoje conhecemos só existe na língua portuguesa falada no Brasil, sendo portando fundamental compreendê-la historicamente como um conceito construído no século XIX. Sobre isto ver: MOTTA, 1998. MOTTA, 2008, pp. 85-102.

${ }^{32}$ ARQUIVO NACIONAL. Ministério da Agricultura. 2a Seção. GIFI. 291. Documento no 451.
} 
o direito de comprar as terras do antigo aldeamento que estavam em seu poder. Os leitores mais atentos perceberão se tratar exatamente do sítio onde morava o inspetor de quarteirão, Manuel Francisco Jatobá Canuto, o mesmo que entrara em conflito com os índios que supostamente fazerem roças em seu terreno. Como prova a seu favor, Menezes apresenta "um translado de escritura pública da compra que fizera, em 25 de junho de 1875, da propriedade 'Espinho' a Manoel Francisco Jatobá e seus herdeiros". ${ }^{33} \mathrm{O}$ ano da alienação coincidia com a nomeação do engenheiro Luiz José da Silva, responsável por proceder com as medições e as demarcações das áreas dos extintos aldeamentos da província de Pernambuco, entre os quais as terras do Riacho do Mato. ${ }^{34}$ De acordo com o decreto de nomeação do engenheiro, ele deveria proceder a verificação dos terrenos pertencentes aos "respectivos patrimônios e mais trabalhos que lhes são correlativos [...] preste auxílios, informações e esclarecimentos, mediante os quais se facilite o desempenho de sua comissão". ${ }^{35}$ Caberia, portanto, efetuar a legitimação de posses de acordo com os termos do Regulamento da Lei de Terras, de 1854, em especial os artigos 22 e 23, que versavam sobre a revalidação e legitimação das terras, originalmente adquiridas por posses ou concessões de sesmarias.

Existiram indícios sobre a ilegalidade do negócio jurídico celebrado por Canuto e o padre Barboza Menezes. ${ }^{36}$ Ao ser consultado pela Diretoria de Agricultura sobre aquelas terras, o engenheiro José Luiz da Silva declarou:

\footnotetext{
${ }^{33}$ ARQUIVO NACIONAL. Ministério da Agricultura. 2a Seção. GIFI. 291. Documento no 451.

34 DECRETO no 273 - Agricultura, Comércio e Obras Públicas - Remete cópia das Instruções expedidas ao Engenheiro Luiz José da Silva para proceder, nos extintos aldeamentos da Província de Pernambuco à verificação de terrenos pertencentes aos respectivos patrimônios e mais trabalhos que Ihe são correlativos. In: A legislação indigenista do século XIX foi compilada na obra de Cunha, Manuela L. C. (org.) Legislação indigenista no século XIX. São Paulo: Edusp; Comissão pró-Índio, 1992, pp. 286-90.

35DECRETO no 273 - Agricultura, Comércio e Obras Públicas - Remete cópia das Instruções expedidas ao Engenheiro Luiz José da Silva para proceder, nos extintos aldeamentos da Província de Pernambuco à verificação de terrenos pertencentes aos respectivos patrimônios e mais trabalhos que Ihe são correlativos. In: A legislação indigenista do século XIX foi compilada na obra de Cunha, Manuela L. C. (org.) Legislação indigenista no século XIX. São Paulo: Edusp; Comissão pró-Índio, 1992, p. 286.

36 Face a recorrência dos conflitos de terra e as reiteradas denúncias acerca das fraudes realizadas pela família Canuto, salta a atenção que o sítio Espinho tenha sido vendido exatamente nessa conjuntura. Uma trapaça bastante conhecida no Brasil, em geral realizada por pessoas bem relacionadas, que consiste em vender terrenos com limites desconhecidos e/ou títulos precários, regularizando-os no nome do adquirente, por meio do ato da compra. Em alguns casos as partes estabelecem a promessa de compra e venda, mas o pretenso comprador desiste do negócio antes de finalizá-lo, permitindo ao alienante registrar o terreno falsamente negociado em seu nome. A Lei Hipotecária de 1864, quatorze anos após a Lei de Terras, buscou estabelecer as regras de alienação de propriedade. Definiu, portanto que a transcrição da escritura de compra e venda no Registro Geral de Imóveis não representava prova de propriedade para o adquirente, mas indicava apenas a existência de uma negociação. Procurava, com isso, evitar a produção de provas fraudulentas por meio de negociações forjadas. O parágrafo 4o do artigo 8, cujo texto determinava essa regra, foi
} 
[...] muito antes do peticionário haver comprado a M. de F. Jatobá Canuto e outros o engenho "Espinho", se tinha feito a medição e a demarcação do perímetro do aldeamento [Riacho do Mato] que foi realizado em 1868, sem aprovação de Jatobá Canuto e outros [...] confinantes [...].

Em junho de 1875, no efetuar-se a divisão de lotes pelas familias dos indios, reconheci que uma parte da superfície do aldeamento achava-se usurpada pelo [...] Canuto e outros [...].

Nas terras usufruídas ilegalmente pelo [...] Canuto e outros e depois pelo suple. [ $\mathrm{P}^{\mathrm{e}}$. Barboza de Menezes] estão compreendidos 25 lotes representando uma área igual a $7.325 .545 \mathrm{~m}^{2}[\ldots]$ e 0 perímetro de 24.623 braças $[\ldots]^{37}$.

Em seu laudo, o engenheiro procurou reconstruir o factual daquelas terras. Expôs ao leitor parte dos detalhes omitidos pelo suplicante, padre José Barboza Menezes, deixando claro que as terras do sítio Espinho, ou pelo menos parcela dela, foram ocupadas ilegalmente por Canuto e, depois da transmissão entre vivos, por Barboza Menezes. A despeito da existência de um translado de escritura pública da compra, anexada ao requerimento, o solicitante não possuiria sobre aquelas terras os direitos que afirmava. As pressões dos índios do extinto aldeamento do Riacho do Mato, durante o processo de demarcação, trouxeram a nu a ilegalidade dos domínios de Canuto. O potentado atuou buscando transferir os direitos, que não possuía, para José Barboza Menezes. Esse último, por sua vez, ciente da ilegalidade de seus domínios, solicitou ao governo que the fossem vendidos os direitos sobre aqueles quinhões. Uma manobra envolvendo documentos falsos que, aliados às brechas legislativas construía, passo a passo, uma nova realidade de ocupação e, portanto, novos direitos sobre as terras. ${ }^{38}$

O texto do engenheiro segue discorrendo sobre os quinhões em litígio, criando condições para uma eventual venda das áreas, pois "estando os ditos lotes desocupados pode-se atender o requerimento". 39 O regulamento de 1854 determinava, em seu artigo no 20 , que não deveriam ser respeitadas as posses estabelecidas após a publicação desse documento, mas o engenheiro parecia

defendido por jurisconsultos justamente sob o argumento de que atribuir ao RGI prova de propriedade absoluta possibilitava que acontecesse a fraude acima referida. Mas, como o texto jurídico pode ser interpretado por diversos caminhos, uma determinada interpretação da Lei de 1864 acabou por abrir a possibilidade de atos de compra e venda não serem matriculados no RGI, permitindo que adquirentes continuarem operando escrituras de compra e venda como prova dominial. Mais detalhes sobre a Lei Hipotecária de 1864 e a utilização da alienação de imóveis como forma de falsificar propriedade, no século XIX, em: RODRIGUES, 2016.

${ }^{37}$ ARQUIVO NACIONAL. Ministério da Agricultura. 2a Seção. GIFI. 291. Documento no 451.

${ }^{38}$ Sobre a recorrência desta estratégia de falsificação dominial ver: RODRIGUES, 2016.

${ }^{39}$ ARQUIVO NACIONAL. Ministério da Agricultura. 2a Seção. GIFI. 291. Documento no 451. 
ignorar essa disposição. Ele seguia emitindo parecer favorável à alienação desses terrenos para o requerente, estabelecendo "[...] o preço de cem réis por braça quadrada, além das despesas com a medição e demarcação já satisfeitas pelo governo e que devem ser pagas à vista pelo sup $\mathrm{l}^{\mathrm{e}}$ "40. $\mathrm{O}$ engenheiro ainda calculou 0 preço final, de acordo com sua proposta, para aquelas terras, "[...] no caso de que se trata a importância devida pela compra dos 25 lotes soma - três contos seiscentos seis mil, setecentos trinta sete réis $[\ldots]^{\prime 41}$. O procurador fiscal da tesouraria da Fazenda, em parecer de 14 de maio de 1877, concordou com a proposta do engenheiro, acrescentando que caberia ao governo decidir sobre venda, se seria realizada em hasta pública ou fora dela. ${ }^{42}$ Os despachos seguintes seguem igualmente o caminho delineado pelo engenheiro. A tesouraria da Fazenda certifica sua concordância "com o respectivo Procurador Fiscal" ${ }^{43}$. A presidência da província de Pernambuco, por sua vez, afirma que fez "simplesmente a remessa de todos os papéis a este ministério" 44. A Inspetoria-Geral de Terras e Colonização, por fim, "nada obsta a que seja efetuada a venda das terras de que de hasta em hasta pública, devendo a comprovação" 45 .

Mesmo com a sequência de pareceres afinados com a proposta da venda, a contenda não se finda por aí. Na sequência do processo, despontaram algumas dúvidas sobre o número de lotes requeridos, se seria um total de 25 ou 26 lotes. É nesse ponto que observamos a primeira intervenção de Machado de Assis no processo, que, em 6 de agosto de 1877, subscreve ao texto do funcionário, destacando "convém primeiramente obter informações acerca do número exato de lotes". ${ }^{46}$ Deixava claro, portanto, que pouco se poderia fazer diante daquela realidade na qual nem mesmo o quantitativo dos lotes era preciso.

Outro funcionário com assinatura desconhecida anunciou, em seguida, o recebimento das informações sobre os lotes. O engenheiro Luís José da Silva, através da presidência de Pernambuco, teria informado que o padre Barboza Menezes pretendia 25 lotes de terras devolutas do extinto aldeamento Riacho do Mato. Redefinia ainda o preço a ser pago pelo suplicante e propunha reunir a Inspetoria-Geral de Terras e Colonização. ${ }^{47}$ Após a proposta, seguiram

\footnotetext{
40 ARQUIVO NACIONAL. Ministério da Agricultura. 2a Seção. GIFI. 291. Documento no 451.

${ }^{41}$ ARQUIVO NACIONAL. Ministério da Agricultura. 2a Seção. GIFI. 291. Documento no 451.

${ }^{42}$ ARQUIVO NACIONAL. Ministério da Agricultura. 2a Seção. GIFI. 291. Documento no 451.

43 ARQUIVO NACIONAL. Ministério da Agricultura. 2a Seção. GIFI. 291. Documento no 451.

${ }^{44}$ ARQUIVO NACIONAL. Ministério da Agricultura. 2a Seção. GIFI. 291. Documento no 451.

${ }^{45}$ ARQUIVO NACIONAL. Ministério da Agricultura. 2a Seção. GIFI. 291. Documento no 451.

${ }^{46}$ ARQUIVO NACIONAL. Ministério da Agricultura. 2a Seção. GIFI. 291. Documento no 451.

${ }^{47}$ ARQUIVO NACIONAL. Ministério da Agricultura. 2a Seção. GIFI. 291. Documento no 451.
} 
respectivamente a palavra "concordo" e a assinatura de Machado de Assis. Os documentos encontrados apresentam mais uma manifestação dele, na qual dialoga com o discurso da Inspetoria-Geral de Terras e Colonização. Machado acata a utilização realizada por esse órgão do aviso de 13 de junho de 1863 na determinação do preço a ser pago por Barboza Menezes. ${ }^{48}$

As intervenções de Machado de Assis, nesse e em vários outros processos encontrados no Arquivo Nacional, se restringem a palavra "concordo" ou reafirmam decisões já emitidas pelos seus colegas. Ao contrário de outros funcionários, ele foi econômico nas palavras. O caso exposto, iniciado pelo requerimento de Barboza Menezes, comprova, entretanto, que Machado lidou diretamente com embates nos quais fazendeiros buscaram, por meio da posse, apropriar-se de terras então ocupadas e pertencentes aos grupos indígenas. O processo chega ao fim com um parecer datado de 30 de outubro de 1877, afirmando:

Estando terminada a discriminação das terras do extinto aldeamento do Riacho do Mato, é meu parecer que sejam vendidos em hasta pública os lotes pretendidos e bem assumi sobre os que estiverem disponíveis, adicionando-se ao preço dos lotes e custos da medição.

Esta medida impedirá que sejam novamente usurpadas as terras pertencentes ao aludido aldeamento. ${ }^{49}$

O redator do parecer propõe a venda em hasta pública, pretendia evitar que as terras do aldeamento do Riacho do Mato continuem o processo de espoliação em curso. Assim, Machado de Assis e seus colegas tiveram conhecimento, dentro dos limites impostos pela vivência no campo decisório do qual atuavam, das arbitrariedades e conflitos de terras ocorridos no Brasil Império. Nesse aspecto, o Machado de Assis literato e o funcionário público destoam no tocante à questão agrária. De um lado, temos o bruxo do Cosme Velho que trabalhou diretamente com processos nos quais o problema fundiário foi aventado, mas predominantemente ratificou os pareceres de seus colegas. De outro lado, o contista escreveu um texto debochando das noções de propriedade típicas da família senhorial oitocentista, "Na Arca: três capítulos (inéditos) das gênesis".

\footnotetext{
${ }^{48}$ ARQUIVO NACIONAL. Ministério da Agricultura. 2a Seção. GIFI. 291. Documento no 451.

${ }^{49}$ ARQUIVO NACIONAL. Ministério da Agricultura. 2ª Seção. GIFI. 291. Documento nº 451.
} 


\section{Considerações Finais}

Ao longo do texto em tela, visitamos dois processos que apresentavam realidades específicas sobre uma mesma questão: os conflitos de terra no Brasil Imperial. Voltados para suas próprias querelas, juntos os processos nos ajudam a evidenciar a pluralidade e a profundidade dos conflitos de terra na segunda metade do século XIX, quando, mesmo com a promulgação da Lei de Terras ainda era necessário lidar com pontos como aforamentos territoriais e disputas por terras de aldeamentos indígenas.

Os processos foram localizados na segunda seção da Diretoria de Agricultura do Ministério de Agricultura Comércio e Obras Públicas, no âmbito de um projeto mais amplo, que volta a preocupação para a atuação de Machado de Assis. Foram muitos e diversos os processos que passaram por sua gestão frente à mencionada diretoria, o que nos revela que o escritor teve intenso contato com os conflitos agrários oitocentistas.

Machado trabalhou e ocupou-se de perto com os temas que circundavam as dificuldades do Império em reformar a estrutura fundiária. O ideário liberal mais progressista da época propugnava eliminar as propriedades repartidas e demarcar os limites fundiários, individualizando o solo e consolidando uma nova forma, supostamente mais eficiente, de possuir as terras. Os dois processos apresentados demonstram, cada um à sua forma, a continuidade das dificuldades do Império em superar aquilo que os liberais considerariam atraso e confusão dominial. Eles apresentam uma fração da realidade social rural com a qual Machado de Assis lidou em seu fazer burocrático, assim como dão uma ideia das contingências nas quais ele exerceu a sua profissão de funcionário público.

No primeiro processo, a moderação conduziu para uma tentativa de eliminar os direitos sobrepostos menos invasiva dentro da perspectiva patriarcal sobre as terras, na qual o espaço privado senhorial deveria ser imune às interferências governamentais. O descontrole estatal sobre o território fazia com que as terras compradas pela Diretoria de Obras Públicas entrassem em demanda, causando uma provável lentidão nas reformas da Floresta da Tijuca, que visavam melhorar a capitação de água na Corte. No segundo caso, a continuidade dos limites territoriais imprecisos, possibilitava conflitos e tentativas de expansão de agentes individuais sobre os domínios indígenas, até então entendidos como um bem coletivo. Mais uma vez, a ingerência estatal sobre a realidade agrária resultava em 
um processo que viria ser solucionado na Diretoria da Agricultura. Dessa vez, causava uma querela fundiária entre indígenas e potentados rurais. A moderação na forma em quem o governo regularizava a estrutura agrária permitia soluções extralegais para o problema, e abria espaço para fraude e violência.

Como já salientado, esse é apenas um pequeno fragmento dos processos agrários que passaram pela pena de Machado de Assis. Ele deixou aos historiadores apenas pistas demasiadamente tímidas com relação ao seu posicionamento no ministério acerca da questão fundiária. Neste sentido, não nos foi possível pensar as concepções machadianas sobre a questão agrária oitocentista. Ainda assim, conseguimos ilustrar algumas nuances da atividade deste escritor no funcionalismo público ministerial, expondo algumas questões tratadas na Diretoria da Agricultura, bem como a forma como os agentes desta instituição as resolveu. Se não conseguimos perceber os posicionamentos individuais desta personagem do Brasil Império, ainda assim apresentamos alguns elementos do campo no qual ele exerceu sua atividade.

\section{REFERÊNCIAS}

ASSIS, Machado. Terras: Compilações para estudo. Rio de Janeiro: Imprensa Nacional, 1886.

ASSIS, Machado. "Três capítulos inéditos do Gênesis". O Cruzeiro. n. 133. Rio de Janeiro. p. 1, 14 de maio, 1878.

CHALHOUB, Sidney. Machado de Assis historiador. São Paulo: Cia das Letras, 2003.

CUNHA, Manuela L. C. (org.). Legislação indigenista no século XIX. São Paulo: Edusp; Comissão Pró-Índio, 1992.

ENGEL, Magali G. "Guerra dos Cabanos". VAINFAS, Ronaldo. Dicionário do Brasil Imperial. Rio de Janeiro: Objetiva, 2002.

MACHADO, Marina Monteiro. "Leis para terras de uma fronteira étnica: A questão indígena no império Brasileiro". GUIMARÃES, Elione; MOTTA, Márcia (org.). Campos em disputa:

História agrária e companhia. São Paulo: ANNABLUME, 2007. Entre Fronteiras: posses e terras indígenas nos sertões (Rio de Janeiro, 1790-1824). Guarapuava: HORIZONTE/UNICENTRO/EDUFF, 2012.

MAGALHÃES JUNIOR, R. Machado de Assis, funcionário público (no Império e na República). Rio de Janeiro: Ministério da Viação e Obras Públicas, 1958.

MAGALHÃES JUNIOR, R. "Machado de Assis, funcionário público". Revista do Serviço Público, Brasília, n. 56, v. 2, pp. 237-248, abr-jun 2005.

MARCONDES, Ayrton. Machado de Assis: Exercício de admiração. São Paulo: A Girafa, 2008. 
MELLO, Janaína Cardoso de. "Matas Plurais, Imoralidades Matrimoniais". PAIVA, Eduardo França; IVO, Isnara Pereira (orgs.). Escravidão, Mestiçagem e Histórias Comparadas. São Paulo; Belo Horizonte: Annablume; PPGH-UFMG, 2008.

MELLO, Janaína Cardoso de. "Dívida de Sangue. Queixas orçamentárias e declínio de produtividade agrícola na guerra dos cabanos (Alagoas - Pernambuco/ 1832 - 1835)". Anais do I colóquio do Laboratório de História econômica e Social (LAHES) da UFJF, 2005, Juiz de Fora. p. 1.

MOTTA, Márcia Menendes. Nas fronteiras do poder: conflitos e direito à terra no Brasil do século XIX. Vício de leitura: Rio de Janeiro, 1998.

MOTTA, Márcia Menendes. "Posseiro no oitocentos e a construção do mito invasor no Brasil (1822-1850)". MOTTA, Márcia; ZARTH, Paulo (orgs.). Formas de Resistência

Camponesa. Visibilidade e Diversidade dos conflitos ao longo da história. São Paulo: UNESP, 2008. pp. 85-102.

MOTTA, Márcia Menendes. Direito à terra no Brasil: a gestação do conflito - 1795-1824. São Paulo: Alameda, 2009.

MOTTA, Márcia Menendes; MACHADO, Marina. "Sobre enfiteuses e outros termos: uma análise sobre os conceitos do universo rural”. História: Debates e tendências, v 17, n 2 , pp. 261-274, jul-dez, 2017.

MELLO, Janaína Cardoso de. "Matas Plurais, Imoralidades Matrimoniais" PAIVA, Eduardo França; IVO, Isnara Pereira (orgs.). Escravidão, Mestiçagem e Histórias Comparadas. São Paulo; Belo Horizonte: Annablume; PPGH-UFMG, 2008.

OLIVEIRA, Maria Luiza Ferreira de. "As Guerras nas Matas de Jacuípe". CLIO - Revista de Pesquisa Histórica, n.33.2, UFPE, Recife, jul. 2015.

PEDROZA, Manoela. “Desafios para a história dos direitos de Propriedade no Brasil”. Em Perspectiva [online], PPGH/UFC, v. 2, n. 1, pp. 7-33, 2016.

RODRIGUES, Pedro Parga. As frações da classe senhorial e a Lei Hipotecária de 1864. Niterói: Eduff, 2016.

RODRIGUES, Pedro Parga. "Machado de Assis e o universo rural: a desconstrução do imaginário senhorial". GALDEZ, Márcia Milena Ferreira; FERRERAS, Norberto Oswaldo; ROCHA, Cristiana Costa da (orgs.). Histórias Sociais do Trabalho: Usos da terra, controle e resistência. São Luís: Café \& Lápis; Editora UEMA, 2015. pp. 163-181.

RODRIGUES, Pedro Parga. "A Lei de Terras de 1850 e os Relatórios do Ministério da Agricultura entre 1873-1889". Revista Maracanan, Rio de Janeiro, n. 17, pp. 103-117, jul.dez. 2017.

SARTORELLI, Isabel Cristina; MARTINS, Eliseu. Machado de Assis, Guarda Livros? Estudos Avançados, v. 30, n. 88, 2016.

SILVA, Edson Hely. “Uma guerra civil de 12 anos': mobilizações indígenas na Zona da Mata Sul de Pernambuco, na segunda metade do século XIX". XVII Encontro de História da Anpuh-Rio: entre o local e o global, 2016.

SILVA, Edson Hely. O lugar do índio. Conflitos, esbulhos de terras e resistências indígenas no século XIX: O caso de Escada-PE (1860-1880). 1995. Recife: Universidade Federal de Pernambuco. Dissertação (Mestrado em História). 


\section{NOTAS DE AUTOR}

\section{CONTRIBUIÇÃO DE AUTORIA}

Pedro Parga Rodrigues - Concepção. Coleta e análise de dados. Elaboração do manuscrito. Participação ativa da discussão dos resultados. Revisão e aprovação da versão final do trabalho Marina Monteiro Machado - Concepção. Elaboração do manuscrito. Participação ativa da discussão dos resultados. Revisão e aprovação da versão final do trabalho.

\section{FINANCIAMENTO}

O presente trabalho foi realizado com os seguintes apoios: INCT Proprietas; Coordenação de Aperfeiçoamento de Pessoal de Nível Superior - Brasil (CAPES) - Código de financiamento 001; Conselho Nacional de Desenvolvimento Científico e Tecnológico - CNPq - Brasil, no edital Universal n 28/2018. Número do processo: 405895/2018-6; Fundação Carlos Chagas de Apoio a Pesquisa no Estado do Rio de Janeiro (FAPERJ) - Edital Prociência 2018.

\section{CONSENTIMENTO DE USO DE IMAGEM}

Não se aplica.

\section{APROVAÇÃO DE COMITÊ DE ÉTICA EM PESQUISA}

Não se aplica.

\section{CONFLITO DE INTERESSES}

Não se aplica.

\section{LICENÇA DE USO}

Este artigo está licenciado sob a Licença Creative Commons CC-BY. Com essa licença você pode compartilhar, adaptar, criar para qualquer fim, desde que atribua a autoria da obra.

\section{HISTÓRICO}

Recebido em: 27-05-2019

Aprovado em: 25-09-2019 